\title{
THE ROLE OF PHENOLICS IN AGARWOOD FORMATION OF Aquilaria crassna Pierre ex Lecomte AND Aquilaria microcarpa Baill TREES
}

\author{
Eka Novriyanti ${ }^{1,2}$ and Erdy Santosa ${ }^{3}$
}

\begin{abstract}
Phenolic is well known as a secondary metabolite that plays an important role in plant defense system. Information about the fungi-impeded role of secondary metabolite is important in achieving success of artificial agarwood production, in that fungi induction imparted to the selected potential trees will be more effective and efficient. This research was aimed to investigate the correlation of agarwood tree phenolics in relation with the susceptibility of corresponding trees to Fusarium solani attack in the formation of agarwood and observing total phenolics content of Aquilaria crassna and Aquilaria microcarpa trees prior to inoculation. Twenty trees of A. microcarpa at Carita, a Forest Area for Special Function (FASF) and ten of A. crassna at Dramaga Research Forest were inoculated with isolate of $F$. solani in spiral pattern around their stem from ground level to about $1.5 \mathrm{~m}$ in height. Prior to inoculation, wood strips were taken off from the stem for total phenolics content. The result revealed that total phenolics content and infection area tended to have a negative correlation. Since the quantity of agarwood is highly related with the infection area, then trees with lower phenolics content should be selected for the more effective and efficient artificial agarwood production.
\end{abstract}

Keywords: Agarwood-producing trees, Fusarium solani, inoculation, phenolics content, infection area

\section{INTRODUCTION}

Agarwood, the wood of the God, has high appreciation due to its multiuse and high economic value. It is actually, a resinous matter accumulated in the wood tissue as the corresponding trees respond to pathogen attack or environmental stress (BSN, 1999; Barden et al., 2000). This exalted commodity is yielded from some tropical trees of Thymeleaceae family, whereas two of its most sought genera, Aquilaria and Gyrinops, have been listed in Appendix II CITES due to the declination of the natural resources (CITES, 2004).

\footnotetext{
${ }^{1}$ Research Institute of Fiber Producing Forest, FORDA, Jl. Raya Bangkinang-Kuok km 9 Kampar Riau.

${ }^{2}$ Corresponding Author: kee_november09@yahoo.com

${ }^{3}$ Forest Microbiology Laboratory, Forest Conservation and Rehabilitation Research and Development Center, Jl. Gunung Batu No. 5, Bogor, 16610
} 
Agarwood formation is poorly understood, even in their natural habitat. However, it is assumed that the formation is triggered when the plants are under stress because of environmental condition or pathogen attack. Thus, the formation process of agarwood in the stem is considered as chemically plant defense mechanisms against unfavorable condition. Therefore, when artificial agarwood is believed as a promising effort to offset the lack of wild stock (Barden et al., 2000; Akter and Neelim 2008; Subiakto et al., 2011), it is essential to study the chemical defense of the plant so that treatment given to the selected potential trees will be more effective and efficient. Moreover, knowledge of agarwood tree's chemical defense system is important in achieving success of artificial agarwood production.

Phenolics is an organic compound characterized by hydroxyl group (-OH) that are bounded to benzene or other complex-aromatic rings (Lattanzio et al., 2006; Bhattacharya et al., 2010). Phenolics are hydrophilic compound that includes stilbene, lignan, hydrolysable tannin, condensed tannin, and flavanoids in this compound group (Sjostrom, 1995). These phenolics are believed for their role in plant defense system. Those compounds typify plants secondary metabolites that are abundantly existed in plants, including enormous groups of bioactive content (Marinova et al., 2005). Some studies have defined phenolics as anti-fungal compound. Carboxylic acid and furan derivates (Xiros et al., 2010), vanillic and caffeic acid (Samapundo et al., 2007), also cinnamic acid (Ponts et al., 2011) are among phenolic acids that were reported to be capable in inhibiting the growth of Fusarium spp. Phenolics containing compound such as eusiderin, a neo lignan that was extracted from ulin wood (Eusideroxylon zwageri) (Syafii et al., 1985) and angolensin from Pterocarpus indicus wood is toxic to Coriolus versicolor and Tyromyces polutris wood rot fungi (Pilotti et al., 1995). Shieh and Sumimoto (1992) isolated some cedrol compounds from wood of Cunninghamia lanceolata that had anti fungal activity. Meanwhile, lignan, a product of oxidative reaction of polyphenol by $\beta-\beta$ linkage, was reported to have inhibitory effect on fungal growth (Céspedes et al., 2006; Cho et al., 2007). In many cases, total phenol content was identified for its effect on plant resistance against disease. Total phenol is increasing at infected cell, indicating that phenol is synthesized during infection or being transported from surrounding tissues (Vidhyasekaran, 2000).

Agarwood is denoted as phytoalexin compounds of the producing-tree. The agarwood resin is considered as plant secondary metabolite produced as its responses to infection or stress. The healthy tree never produced the exalted scent secondary metabolite that could only be found in under stressed one (Yuan et al., 1992; Isnaini, 2004).

This paper presented a study on a relation of phenolics content in agarwoodproducing trees with the agarwood formation that was artificially induced by Fusarium solani fungus. It was assumed that lower phenolics content would give larger infection area on the stem, which indicated the corresponding tree was more susceptible to the agarwood formation. Here, the infection area reflected the quantity of agarwood 
produced. The objectives of this study were to investigate the pre-inoculation total phenolics content of $A$. crassna and $A$. microcarpa that were represented by wood strips; and the correlation of total phenolics content with the susceptibility of $A$. crassna and $A$. microcarpa in the agarwood formation.

\section{MATERIALS AND METHODS}

The samples consisted of ten $A$. crassna trees in Dramaga Research Forest and twenty trees of $A$. microcarpa at Forest Area for Special Function (FASF), Carita. The trees were about 10 years old (1998 plantation). Juice inoculants of $F$. solani were obtained from Laboratory of Forest Microbiology at the Forest Conservation and Rehabilitation Research and Development Center, Bogor.

\section{A. Pre-Inoculation Sampling}

Inoculation was deployed in a spiral pattern at stem area extending from the ground level to $1.5 \mathrm{~m}$ in height, wood strips were taken from that area representing preinoculation total phenolics condition (Figure 1). Those samples comprised of wood strips with dimension of $3 \times 3 \mathrm{~cm}$, which was further transformed into wood mills that passed through 40 mesh but retained on 60 mesh.
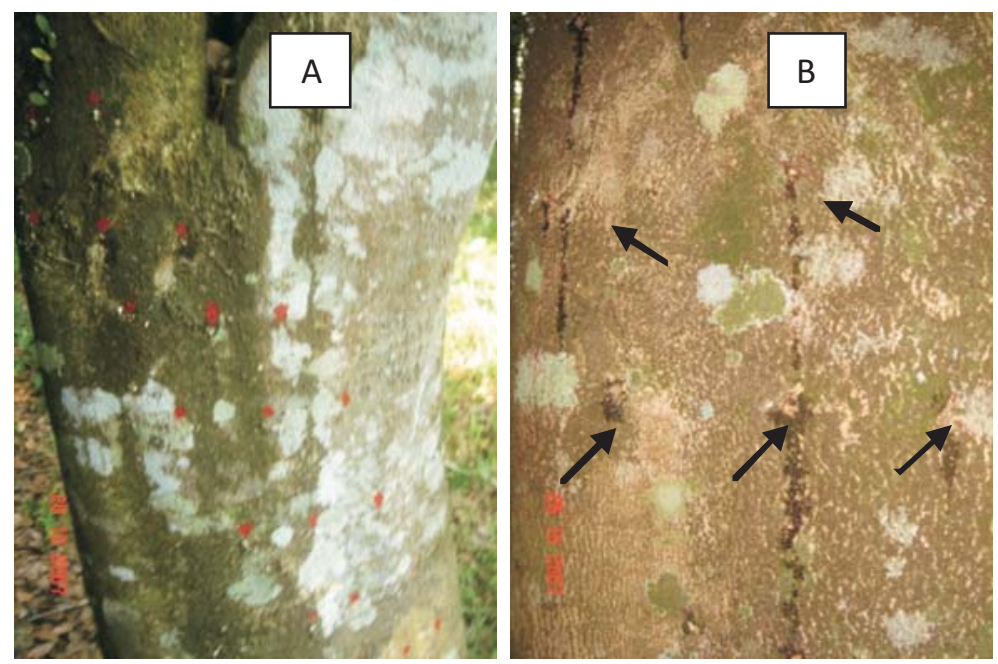

Figure 1. Inoculation pattern on the stem of agarwood trees

Notes: The holes marker before drilling (A), The holes after drilling (B) and inoculation (the holes with water dripped) 


\section{B. Analysis of Total Phenolics in Pre-Inoculated Wood Mill}

There were about 30 groups of the collected wood mills, which corresponded to 30 samples ( 20 from $A$. microcarpa and 10 from $A$. crassna). Each of these groups was weighed as much as 1 gram, further extracted by $10 \mathrm{ml}$ of $70 \%$ acetone. The extract solution was then added with $0.5 \mathrm{ml}$ folin ciocalteau reagent $1 \mathrm{~N}$ and $2.5 \mathrm{ml}$ solution of $20 \% \mathrm{Na}_{2} \mathrm{CO}_{3}$. After 15 minutes, the determination of total phenolics content of this solution was carried out using spectrophotometer (Shimadzu, Japan) at UV-visible wavelength $(\lambda)$ of $725 \mathrm{~nm}$. Total phenolics content is expressed as ppm of tannic acid. This method is a modified method of those stated originally by Asami et al. (2003), where Tannic acid was used as standard instead of Gallic acid.

\section{Inoculation Procedure}

Sample trees were inoculated with $F$. solani to induce agarwood formation. The agarwood, which was represented by infection area, was then compared to the phenolics content of the pre-inoculated wood strips. Inoculation was deployed in three spiral patterns around the stem each containing 15 injection holes, thus there were 45 injection holes per tree (Figure 1).

\section{Observation and Data Collection}

Parameter for assessing susceptibility of the trees is infection area. Beside the preinoculation time $(\mathrm{HO})$, there were three consecutive observation times: three days after inoculation (H3); two months after inoculation (B2); and six months after inoculation (B6).

\section{RESULTS AND DISCUSSION}

Total phenolics content varied for each sample tree, the lowest is $0.06 \%(\mathrm{w} / \mathrm{w})$ and the highest is $0.23 \%(\mathrm{w} / \mathrm{w})$ (Figure 2). The average of total phenolics content for each location revealed that the value was significantly higher for trees at Dramaga than for those at Carita, which were $0.18 \%(\mathrm{w} / \mathrm{w})$ and $0.15 \%(\mathrm{w} / \mathrm{w})$, respectively. 


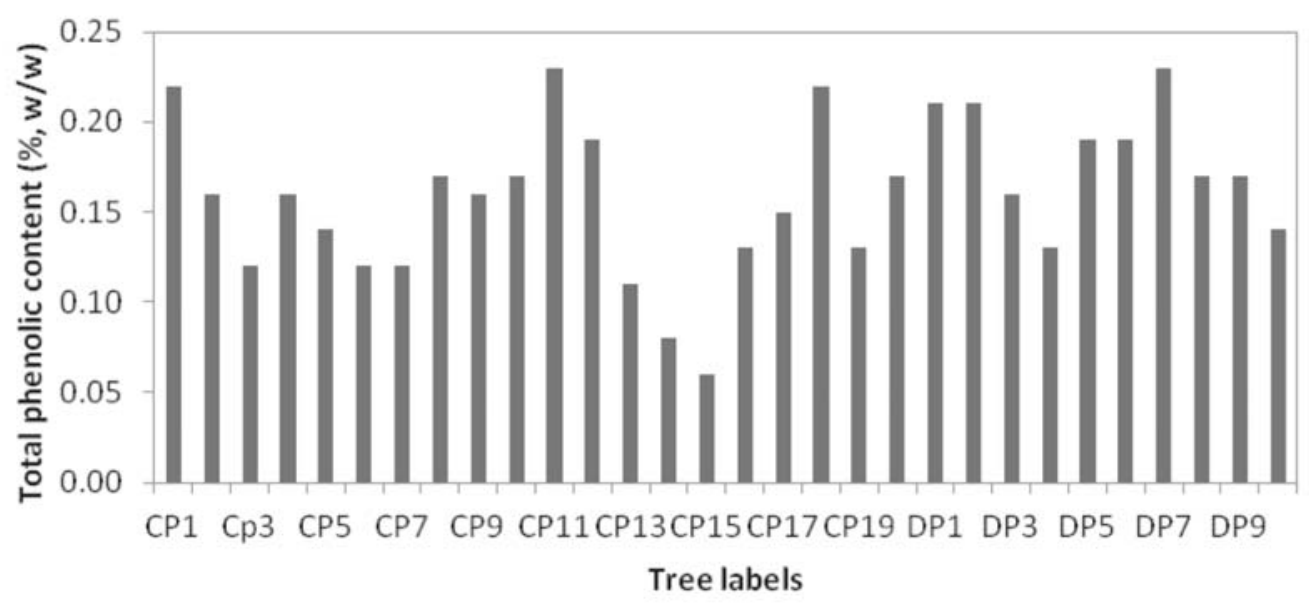

Figure 2. Total phenolics content of pre-inoculated agarwood trees as measured using folin ciocalteu method

Notes: CP: A. Microcarpa trees at Carita $(i=1,2,3, \ldots, 20)$; DP: $A$. crassna trees at Dramaga $(j=1,2$, $3, \ldots, 10)$

The extent of infection in the vertical or lengthwise direction was longer than in the horizontal or transverse direction (Table 1). This result was due to anatomical factors of tree (i.e. bark and wood) which is predominant in the vertical direction (i.e. pores, axial fibers and longitudinal parenchyma) compared to those in the transverse direction (ray cells), that further facilitated the vertical spread of nutrient and water movement. As a result, the spread of the fungi became quicker and faster in the vertical direction than in the horizontal direction. However, the extent of infection in the lengthwise direction between the two sites was not different while it was significantly different in the transverse direction, which was higher at Carita that probably had caused the higher infection area at Carita than that at Dramaga. 
Table 1. Total phenolics content of pre-inoculated agarwood trees and infection area of the corresponding species after six months inoculation with $F$. solani

\begin{tabular}{|c|c|c|c|c|}
\hline \multirow{2}{*}{ Tree no. } & \multirow{2}{*}{$\begin{array}{l}\text { Total Phenolics } \\
(\%, \mathrm{w} / \mathrm{w})\end{array}$} & \multicolumn{3}{|c|}{ Infection } \\
\hline & & Length (mm) & Width (mm) & Extent $\left(\mathrm{mm}^{2}\right)$ \\
\hline \multicolumn{5}{|c|}{ A. microcarpa } \\
\hline CP15 & 0.06 & 27.5 & 10.5 & 188.0 \\
\hline CP14 & 0.08 & 50.0 & 15.0 & 490.0 \\
\hline CP13 & 0.11 & 32.0 & 10.0 & 263.0 \\
\hline CP6 & 0.12 & 68.0 & 11.0 & 498.0 \\
\hline $\mathrm{CP} 3$ & 0.12 & 33.5 & 10.0 & 230.0 \\
\hline $\mathrm{CP7}$ & 0.12 & 41.5 & 12.5 & 331.0 \\
\hline CP19 & 0.13 & 25.0 & 8.0 & 124.0 \\
\hline CP16 & 0.13 & 26.5 & 10.8 & 168.5 \\
\hline CP5 & 0.14 & 59.0 & 20.5 & 712.0 \\
\hline CP17 & 0.15 & 35.0 & 9.0 & 212.0 \\
\hline $\mathrm{CP9}$ & 0.16 & 41.5 & 13.5 & 382.0 \\
\hline $\mathrm{CP} 2$ & 0.16 & 44.0 & 11.0 & 302.0 \\
\hline $\mathrm{CP} 4$ & 0.16 & 46.0 & 21.5 & 609.0 \\
\hline $\mathrm{CP} 8$ & 0.17 & 21.0 & 9.5 & 152.0 \\
\hline CP10 & 0.17 & 40.0 & 10.0 & 250.0 \\
\hline CP20 & 0.17 & 29.0 & 10.0 & 171.0 \\
\hline CP12 & 0.19 & 32.0 & 11.0 & 226.0 \\
\hline $\mathrm{CP} 1$ & 0.22 & 36.0 & 10.5 & 245.0 \\
\hline CP18 & 0.22 & 36.0 & 10.3 & 221.0 \\
\hline CP11 & 0.23 & 44.0 & 9.0 & 254.0 \\
\hline Average & 0.15 & 38.4 & 11.7 & 301.4 \\
\hline \multicolumn{5}{|l|}{ A. crassna } \\
\hline DP4 & 0.13 & 49.5 & 8.0 & 194.5 \\
\hline DP10 & 0.14 & 22.0 & 4.5 & 47.5 \\
\hline DP3 & 0.16 & 27.0 & 7.0 & 113.0 \\
\hline DP9 & 0.17 & 24.5 & 6.0 & 80.5 \\
\hline DP8 & 0.17 & 36.5 & 6.5 & 148.0 \\
\hline DP5 & 0.19 & 43.8 & 7.8 & 167.5 \\
\hline DP6 & 0.19 & 25.0 & 6.3 & 103.5 \\
\hline DP1 & 0.21 & 39.8 & 10.5 & 273.5 \\
\hline DP2 & 0.21 & 43.5 & 10.5 & 207.5 \\
\hline DP7 & 0.23 & 31.5 & 5.5 & 107.0 \\
\hline Average & $0.18 \% *$ & $34.3^{\text {ns }}$ & $7.3^{* *}$ & $144.3^{* * *}$ \\
\hline
\end{tabular}

Notes: Trees were ordered based on the total phenolics content; CP: code for tress at Carita region, species of $A$. microcarpa; DP: code for trees at Dramaga region, species of $A$. crassna. * denotes that the value is significantly higher than the opposite treatment (***: $\mathrm{p}<0.001$, **: $\mathrm{p}<0.05$, *: $\mathrm{p}<0.10$ ); 'ns' means that the value is not significantly different from the opposite treatment, analyzed by Two-tailed T-Test. 
In average, the tree infection area at Carita was bigger than that at Dramaga, whereas the total phenolics content at former location was significantly lower than that at the later (Table 1). This fact confirmed the former assumption that the lower the phenolics content, the more susceptible the tree to the attack by $F$. solani, hence the bigger the necrosis.

Total phenolics content and infection area that represent tree susceptibility were plotted into two-dimensional graph in order to assess the tendency of their relation. Total phenolics content and infection area had a tendency of negative correlation (Figure 3) which was indicated by the higher the phenolics content the smaller the infection area tended to be. This result is concomitant with the study by Del Río et al. (2003) that reported the greater inhibition against Phytophthora sp. related with the higher total phenolics content of the extract. The coefficient of determination was quite low $\left(\mathrm{R}^{2}=0.115\right)$ which designated the weak correlation between the two variables. This weak correlation suggested there are another factors beside the phenolics content that had bigger effect to the infection area of the tree.

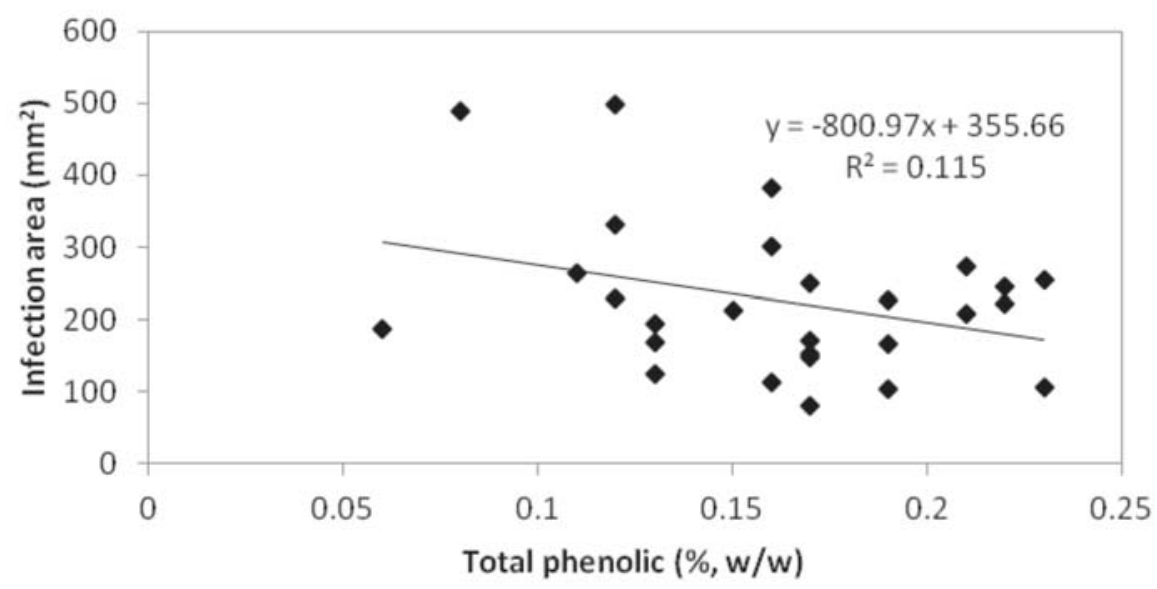

Figure 3. Correlation tendency of total phenolics content and infection area of agarwood trees at Carita and Dramaga, induced by $F$. solani fungi

Negative correlation tendency was also shown when sample trees are distinctly differentiated into research locations/tree species (Figures 4 and 5). Whether it was $A$. crassna at Dramaga or A. microcarpa at Carita, both species showed a tendency of negative correlation between total phenolics content and infection area. Weak correlations also shown at both Carita and Dramaga, coefficient of determination $\left(\mathrm{R}^{2}\right)$ were 0.313 and 0.179 , respectively. 


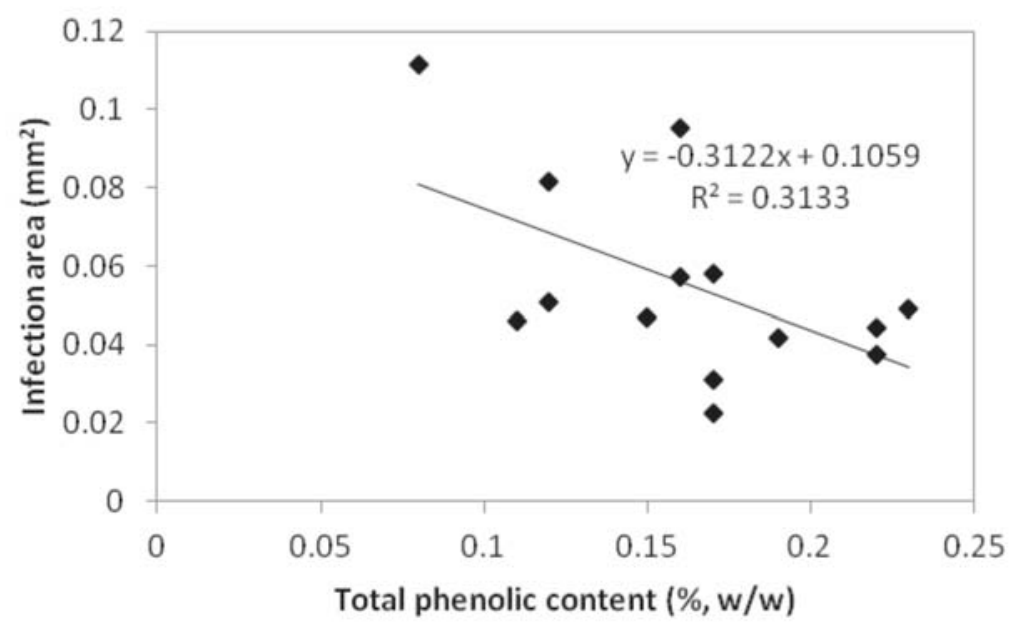

Figure 4. Correlation between total phenolics content and infection area of $A$. microcarpa stem at Carita

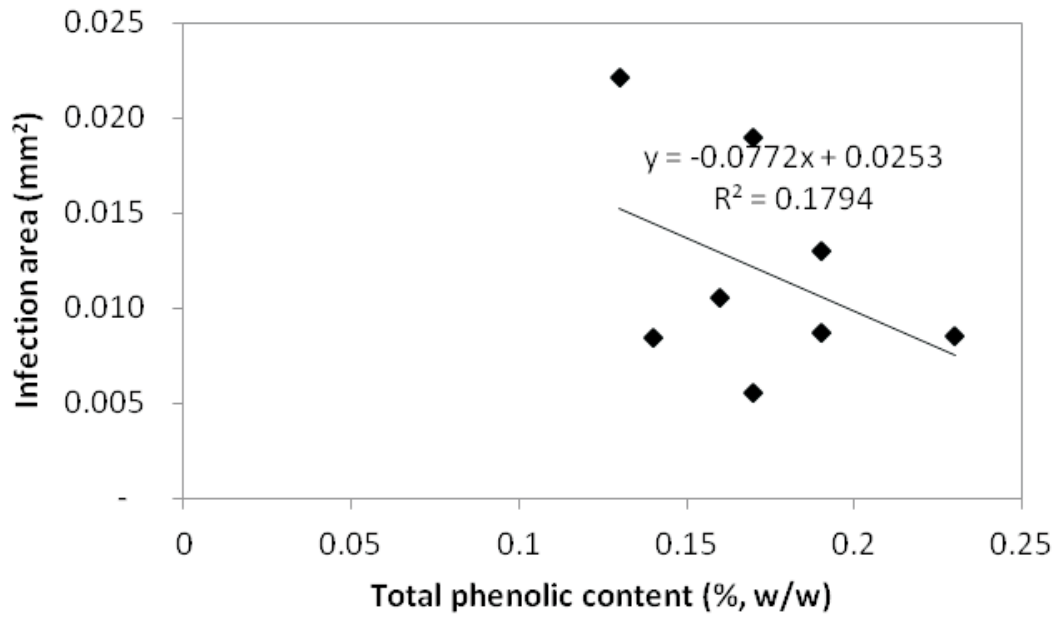

Figure 5. Correlation between total phenolics content and infection area of $A$. crassna stem at Dramaga

In many cases, total phenolics content has been observed to have roles in plant disease resistance. Vidhyasekaran (2000) noted that total phenolics increasing or phenolics accumulation was localized at the infected tissue. When extractives concentration was used as a parameter for tree susceptibility, then the extractives concentration of $A$. crassna tended to have negative correlation with infection area 
caused by F. solani (Figure 6). Although the correlation was weak $\left(\mathrm{R}^{2}=0.259\right)$, the negative correlation indicated that smaller infection occurred if the tree had higher extractives content. However, the weak correlation pointed that the single effect of secondary metabolites, such as extractives and phenolics content to the infection area was weak.

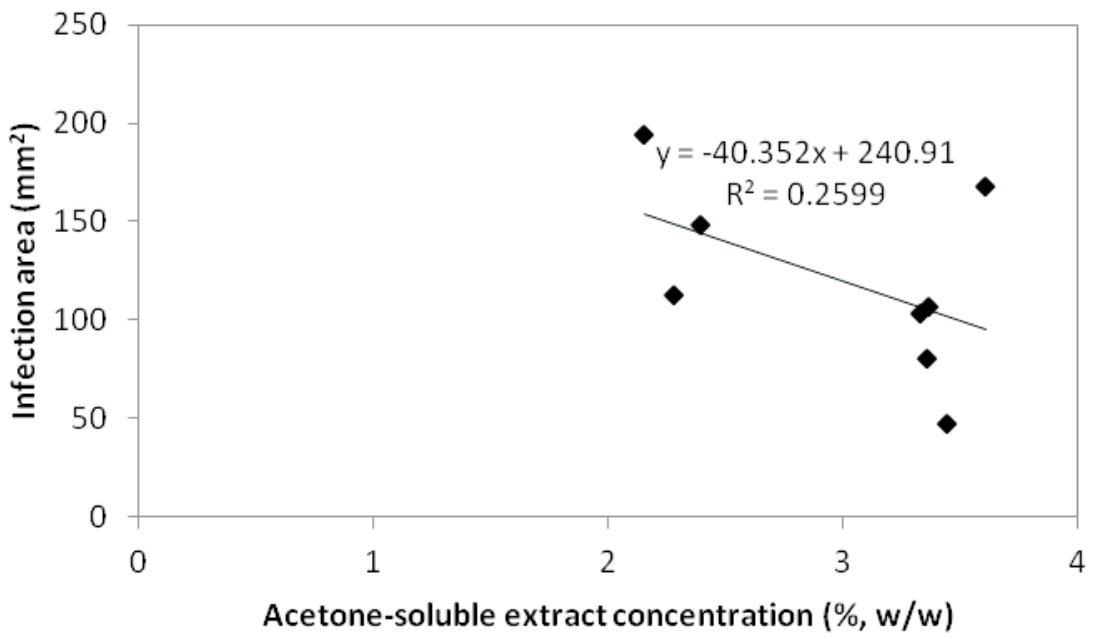

Figure 6. Correlation of acetone soluble extracts concentration of $A$. crassna and infection area induced by $F$. solani

Agarwood is resulted from the tree defense mechanism. However, plants defense is determined by various factors. Haukioja (2003) stated that various mechanisms involved in creating birch defense, tree species that grow in temperate zones. Therefore, a weak correlation between single factors such as total phenolics content with the infection area of the agarwood tree is possible to observe, since the infection was resulted from various mechanism that work altogether.

We assumed that the tree's defense of these agarwood producing-species is triggered by $F$. solani attack. However the formation of necrosis area is not affected by only a single factor of secondary metabolite content, as observed moderately weak correlation between plant's total phenolics content with the infection area. Plant defense is affected by three components, the resistance of the host plant, the virulence of the pathogen or the intensity of the attack and the environmental factors (i.e. humidity, rainfall, air temperature, soil type and fertility, nutrient status, other surrounding plants, etc.) (Agrios, 1997; Turjaman and Santosa, 2011). Therefore, in order to attain achievement in agarwood formation, the secondary metabolite cannot be considered separately with other factors, such as microclimate, site quality, inducer agent and genetic of both host plant and inducer agent. In other word, instead of resulted from a 
single factor, some factors would work altogether in creating successful agarwood formation.

Plants have great abilities in synthesizing aromatic substances, mostly are phenol or its oxygen-substituted derivates (Cowan, 1999). Those substances are secondary metabolites that are frequently active as defense mechanism against microorganism, insects, or herbivore predation. Trees will exert a response to the pressure, like a bad environment, disease invasion and herbivore predation with defense system such as secondary metabolite compounds. The strain sustained at resistant tree will cause higher concentration of defense compounds to be synthesized, whereby the greater the strain intensity the higher the concentration of synthesized compounds. In contrary, those synthesized defense compounds will be less in concentration or not even traced when less-resistant tree suffers harsh condition, because defense compounds synthesized by susceptible tree are not satisfactorily enough in retarding the damage caused by the unfavorable condition (Cowan, 1999).

\section{CONCLUSION}

The total phenolics content of the plant plays a considerable role in the agarwood formation, although it may work more pronouncedly in a system with other various factors rather than only in a single factor. The lower total phenolics content in the tree could result in the larger area of the infection, which means that the larger quantity of agarwood could be yielded or artificially induced.

The finding further suggested considering to select trees with relatively lower total phenolics content in order to acquire more intensive artificial agarwood inducement by using fungi. Trees with relatively lower phenolics content are assumed more susceptible to the agarwood formation. However, since the agarwood formation must be resulted from various aspects, then another factors should be also included in the account.

\section{ACKNOWLEDGEMENTS}

The authors would like to thank the Ministry of Forestry, Government of Indonesia, Laboratory of Forest Microbiology of Forest Conservation and Rehabilitation Research and Development Center and the ITTO Project PD 425/06 Rev.1 (I) for funding the research. Further, the authors full gratitude to M. Turjaman, PhD., Dr. I.R. Sitepu, Prof. W. Syafii, Dr. G. Pari and Prof. S. Achmadi for their valuable help and discussions. After all, appreciation is also presented to all staffs of the Laboratory of Forest Microbiology, especially Mr. Najmulah and Mr. Aryanto for their thorough assistance in the work. 


\section{REFERENCES}

Agrios, G.N. 1997. Plant Pathology. Fourth Edition.Academic Press, California.

Akter, N. and A.Z. Neelim. 2008. Agarwood plantation at BRAC Tea Estate: introduction, environmental factors and financial analysis. BRAC Research Report, July 2008, Dhaka, Bangladesh.

Asami, D.K., Y.J. Hong, D.M. Barrett and A.E. Mitchell. 2003. Comparison of the total phenolics and ascorbic acid content of freeze-dried and air-dried marionberry, strawberry, and corn grown using conventional, organic, and sustainable agricultural practices. Journal of Agricultural. And Food Chemistry 51: 12371241.

Badan Standarisasi Nasional [BSN]. 1999. SNI 01-5009.1-1999: Gaharu. Jakarta.

Barden, A., N.A. Anak, T. Mulliken and M. Song. 2000. Heart of the matter: agarwood use and trade and CITES implementation for Aquilaria malaccensis. www.traffic.org. Downloaded at $22^{\text {nd }}$ of May 2007.

Bhattacharya, A., P. Sood and V. Citovski. 2010. The roles of plant phenolics in defence and communication during Agrobacterium and Rhizobium infection. Molecular Plant Pathology 11 (5): 705-719.

Céspedes, C.L., J.G. Avila, A.M. García, J. Becerra, C. Flores, P. Aqueveque, M. Bittner, M. Hoenesen, M. Martinez and M. Silva. 2006. Antifungal and antibacterial activities of Araucaria araucana (Mol.) K. Koch heartwood lignans. Z. Naturforsch 61c: 35-43.

Cho, J.Y., G.J. Choi, S.W. Son, K.S. Jang, H.K. Lim, S.O. Lee, N.D. Sung, K.Y. Cho and J-C. Kim. 2007. Isolation and antifungal activity of lignans from Myristica fragrans against various plant pathogenic fungi. Pest Management Science 69: 935940.

Convention on International Trade in Endangered Species of Wild Fauna and flora [CITES]. 2004. Amendments to Appendices I and II of CITES. http://www.cites.org/common/cop/13/raw/props/ID-AguilariaGyrinops.pdf.

Cowan, M. 1999. Plant products as antimicrobial agents. Clinical Microbiology Review $12(4): 564582$.

Del Río, J.A., A.G. Báidez, J.M. Botía and A. Ortuño. 2003. Enhancement of phenolic compounds in olive plants (Olea europaea L.) and their influence onresistance against Phytophthorasp. Food Chemistry 83:75-78. 
Forestry Commission GIFNFC. 2007. Chemicals from trees. http://treechemicals. csl.gov.uk/review/extraction.cfm. Downloaded at $14^{\text {th }}$ of July 2007.

Hakkioja, E. 2003. How do birch defense operate. Proceeding IUFRO on Forest insect population dynamic and host influences. Kanazawa, Japan. Pp. 26-30.

Isnaini, Y. 2004. Induction of gubal agarwood production through fungi inoculation and biotic factor application (Dissertation). Graduate School of Institut Pertanian Bogor, Bogor. Unpublished.

Lattanzio, V., V.M.T. Lattanzio and A. Cardinali. 2006. Role of phenolics in the resistance mechanism of plants against fungal pathogens and insect. Phytochemistry Advances in Research: 23-67.

Marinova, D., F. Ribarova and M. Atanassova. 2005. Total phenolics and total flavanoids in Bulgarian fruits and vegetables. Journal of the University of Chemical Technology and Metallurgy 40 (3):255-260.

Pilotti, C.A., R. Kondo, K. Shimidzu and K. Sakai. 1995. An examination of the anti fungal component in the heartwood extracts of Pterocarpus indicus. Journal of the Japan Wood Research Society 4 (6): 593-597.

Ponts, N., L. Pinson-Gadais, A-L. Boutigny, C. Barreau and F. Richard-Forget. 2011. Cinnamic-derived acids significantly affect Fusarium graminearum growth and in vitro synthesis of type B trichothecenes. Phytopathology 101: 929-934.

Samapundo, S., B. De Meulenae, D. Osei-Nimoh, Y. Lamboni, J. Debevere and F. Devlieghere. 2007. Can phenolic compounds be used for the protection of corn from fungal invasion and mycotoxin contamination during storage? Food microbial 24: 465-473.

Shieh, J.C. and M. Shimamoto. 1992. Antifungal wood component of Cunninghamia lanceolata. Journal of the Japan Wood Research Society 38 (5): 482-489.

Sjostrom E. 1995. Wood Chemistry, basic and utilization. Second Edition. In: Sastrohamidjojo, H. (Translator). Prawirohatmodjo, S. (Ed.). Gadjah Mada University Press, Yogyakarta.

Subiakto, A., A. Santoso and M. Turjaman. 2011. Financial analysis on gaharu (eaglewood) plantation. In: Turjaman, M. (Ed.): Bioinduction Technology, for sustainable development and conservation of gaharu. Proceeding of Gaharu Workshop, Bogor, Indonesia. Pp. 59-66.

Syafii, W., T. Yoshimoto and M. Samijima. 1985. Neolignan from the heartwood of ulin wood (Eusideroxylon zwageri). Journal of the Japan Wood Research Society 31(11): 952-955. 
Turjaman, M. and E. Santosa. 2011. Teknologi inokulasi dan perkembangannya untuk menghasilkan gubal gaharu berkualitas tinggi. Http:// gaharublog.files.wordpress.com/2011/05/2-inokulasi-gaharu.pdf. Downloaded at December $21^{\text {st }} 2011$.

Vidhyasekaran, P. 2000. Physiology of Disease Resistant in Plant. CRC Press Inc., Florida.

Xiros, C., C. Vafiadi, T. Pachos and P. Christakopoulos. 2011. Toxicity tolerance of Fusarium oxysporum toward inhibitory compounds formed during pretreatment of lignocellulosic materials. Journal of Chemical Technology and Biotechnology 86: 223-230.

Yuan, Q.S., L. Bi-Yao and Z. Liang-Feng. 1992. Formation of oxo-agarospirol in Aquilaria sinensis. Plant Physiology Communications 28 (5): 336-339. 